Article

\title{
Polyurethane-Carbon Nanotubes Composite Dual Band Antenna for Wearable Applications
}

\author{
Robert Olejník ${ }^{1, *}$, Stanislav Goňa ${ }^{2} \oplus$, Petr Slobodian ${ }^{1}$, Jiří Matyáš ${ }^{1}$, Robert Moučka ${ }^{1}$ \\ and Romana Daňová ${ }^{1}$ (D) \\ 1 Centre of Polymer Systems, University Institute, Tomas Bata University in Zlín, 76001 Zlín, Czech Republic; \\ slobodian@utb.cz (P.S.); matyas@utb.cz (J.M.); moucka@utb.cz (R.M.); danova@utb.cz (R.D.) \\ 2 Faculty of Applied Informatics, Tomas Bata University in Zlín, 76005 Zlín, Czech Republic; gona@utb.cz \\ * Correspondence: olejnik@utb.cz; Tel.: +420-576-031-746
}

Received: 27 October 2020; Accepted: 16 November 2020; Published: 23 November 2020

\begin{abstract}
The design of a unipole and a dual band F-shaped antenna was conducted to find the best parameters of prepared antenna. Antenna radiator part is fully made of polymer and nonmetal base composite. Thermoplastic polyurethane (PU) was chosen as a matrix and multi-wall carbon nanotubes (MWCNT) as an electrical conductive filler, which creates conductive network. The use of the composite for the antenna has the advantage in simple preparation through dip coating technique. Minor disadvantage is the usage of solvent for composite preparation. Composite structure was used for radiator part of antenna. The antenna operates in 2.45 and $5.18 \mathrm{GHz}$ frequency bands. DC conductivity of our PU/MWCNT composite is about $160 \mathrm{~S} / \mathrm{m}$. With this material, a unipole and a dual band $\mathrm{F}$ antenna were realized on $2 \mathrm{~mm}$ thick polypropylene substrate. Both antenna designs were also simulated using finite integration technique in the frequency domain (FI-FD). Measurements and full wave simulations of $S_{11}$ of the antenna showed good agreement between measurements and simulations. Except for $S_{11}$, the gain and radiation pattern of the antennas were measured and simulated. Maximum gain of the designed unipole antenna is around -10.0 and $-5.5 \mathrm{dBi}$ for 2.45 and $5.18 \mathrm{GHz}$ frequency bands, respectively. The manufactured antennas are intended for application in wearable electronics, which can be used to monitor various activities such as walking, sleeping, heart rate or food consumption.
\end{abstract}

Keywords: polymer antenna; composite material; carbon nanotubes; effective permittivity; effective permeability; effective conductivity; wearable electronics

\section{Introduction}

The rise of the Internet of Things (IoT) in the 21st century has seen a pressing need of developing easily incorporable electrochemical devices for acquiring real-time data. One segment of this field comprises smart clothing and wearable electronics, which is used for diverse ends ranging from activity monitoring bracelets, smart watches or glasses over GPS enabled shoes to life-saving devices used in healthcare [1,2]. IoT devices generally consist of a sensing unit collecting vital data and a transmitting unit, which sends the collected data to the processing or display unit. These are typically rigid, conventional electronic parts in the flexible plastic or elastic rubber substrates which presents some limitations in their seamless integration e.g., into clothing. Thus, developing and designing miniature and/or highly flexible IoT devices is highly desirable and currently draws a great deal of interest. Researchers have thus focused on developing wearable formats of electrochemical devices since they can play a vital role in the field of personalized IoT [3-6].

Antenna design which could be used in the segment of wearable electronics often features antennas with non-metallic radiators. If the radiator is to be made of a non-metallic material then this still has to 
have sufficiently high conductivity at microwave frequencies to achieve sufficient radiation efficiency and consequently the highest possible gain. Therefore, conductive textiles, conductive polymers [7] or composite materials are mostly used. Conductive textiles are employed in fabric antennas, which are most frequently in the form of a patch antenna (a rectangular microstrip antenna). These antennas of good radiation characteristics typically consist of upper and lower conductive layers of antenna patch while the ground plane and the middle layer are made of dielectric substrate $[8,9]$.

Another large group of materials used in antenna with non-metallic radiators is conductive polymers. First attempts in the field were made with polyaniline (PANI) composites [10]. Later researchers moved on to the usage of carbon nanotubes $[11,12]$ or other very good conductors (silver and gold particles) to increase electrical conductivity $[13,14]$. The use of carbon nanotubes has led to technologies using PANI and carbon fibers (PANI-MWCNT) $[15,16]$, technologies using polypyrrole (PPy), [17] and PPy combined with PEDOT materials $[18,19]$. Technologies using pure PANI exhibit DC conductivity around $4500 \mathrm{~S} / \mathrm{m}[15,16]$. Polypyrrole materials have conductivity about 2000 S/m [17] and are typically around $100 \mu \mathrm{m}$ thick even though stacking of PPy layers into final thickness of several hundreds of microns is also possible. PEDOT materials have higher conductivity of about $10,000 \mathrm{~S} / \mathrm{m}$ but their thickness is limited approximately to $10 \mu \mathrm{m}$. Small physical thickness and conductivity around 10,000 S/m results in DC sheet resistance of PEDOT materials being larger than the sheet resistance of PPy material [17]. All above-mentioned materials can be used in the design of an antenna having large radiation efficiency. PANI-MWCNT showed radiation efficiency around 60\% [15]. PPy solution also shows radiation efficiency around 60\% [17]. Antennas with PEDOT material have typically lower radiation efficiency of around 30\% [17]. Recently, other approaches in preparation of conductive polymers with polyaniline have appeared in the literature. These approaches are represented by multifunction poly/amide-imid and polyaniline films [20] and highly conductive poly/amide-imid films [21].

Apart from conductive polymers, other non-metal materials can be used in radiating part of microwave antennas with large radiation efficiency. Most common case is the use of composites with long carbon fibers [22] or combination of long carbon fibers with carbon nanotubes [22]. Another solution is the use of pure nanotubes [23]. The approach described in [23] leads to a material with conductivity as high as 50,000 S/m, also known as buckypaper [23]. Conductivity measurement of carbon nanotubes at microwave frequencies was carried out in detail in [24]; conductivity of pure carbon nanotubes is around 160,000 S/m and conductivity of buckypaper is around 50,000 S/m [25]. Through mixing of carbon nanotubes with a dielectric matrix, the effective conductivity of the composite becomes lower than the conductivity of pure nanotubes and strongly depends on its concentration and spatial distribution of carbon nanotubes within the composite [7]. Examples of measurement of the conductivity of composite materials in waveguides can be found in [26,27].

In this paper, a novel approach to preparation of conductive composite material (using a "dip" technique) suitable for antenna's radiator is presented together with an actual antennas design. The novel approach uses a composite comprising polyurethane mixed with multiwall carbon fibers (PU/MWCNT). The advantage of this approach lies in the simplicity of material preparation, which is comparable to polyaniline and polypyrrole, but is significantly less demanding than for PEDOT. As both thickness and conductivity of the PU/MWCNT composite is limited antenna radiators must be made from relatively thick layers (hundreds of microns), to achieve substantial radiation efficiency of antennas. Required thickness is realized by stacking several layers on top of each other. Although from an antenna construction viewpoint, it would be more appropriate to design a dual band antenna of other topology (e.g., a microstrip patch, a slot, or a variant of PIFA antenna), for the sake of simplicity, we decided to study a simple unipole and F-antenna over ground plane. Even though the gain of this approach is smaller, it is still acceptable for short range operating devices; typically, our antennas show gain of -10.0 and $-5.5 \mathrm{dBi}$ at 2.45 and $5.18 \mathrm{GHz}$ frequency band, respectively. The resulting antenna is lightweight and small enough to fit into a pocket and although it is not fully flexible, it can tolerate certain bending; thus could be placed on upper arms or on a thigh, where minimum bending occurs. 


\section{Materials and Methods}

\subsection{Materials}

All the chemicals used were of analytical grade. $N, N$-dimethylformamide $99.5 \%$, analytical reagent grade was purchased from Fisher Chemical (Waltham, MA, USA). Purified multi wall carbon nanotubes (MWCNT) were produced by the chemical vapor deposition (CVD) of acetylene supplied by Sun Nanotech Co. Ltd., Nanchang, Jiangxi, China, China. According to the supplier, the nanotubes have diameters of 10-30 nm, length 1-10 $\mathrm{m}$, purity $>90 \%$ and electrical resistivity $0.12 \Omega \mathrm{cm}$.

A Thermoplastic polyurethane (PU) Desmopan DP 385S was purchased from Bayer MaterialScience, (Leverkusen, Berlin, Germany). According to supplier's specifications PU has following characteristic: strength of $48.9 \mathrm{MPa}$, with the strain at break of $442 \%$ and density of $1.20 \mathrm{~g} \mathrm{~cm}^{-3}$. Polyurethanes (PU) Desmopan ${ }^{\circledR}$ is a thermoplastic block copolymer characterized by a wide range of properties. Its linear polymeric chains consist of alternating flexible, elastic segments. Polyurethane was used as a matrix and it was filled with MWCNT. It serves as an elastic base for the MWCNT antenna radiator layer.

\subsection{Sample Preparation}

Polyurethane solution $10 \mathrm{wt} \%$ in dimethylformamide (DMF) was prepared. The solution was mixed over night at $400 \mathrm{rpm}$ and $90^{\circ} \mathrm{C}$. Subsequently carbon nanotubes were added to the solution and the dispersion was mixed using UP $400 \mathrm{~S}$ ultrasonic homogenizer for $15 \mathrm{~min}$, at power of $50 \%$ and at pulse of $50 \%$. Then the dispersion was mixed mechanically using a magnetic stirrer for $30 \mathrm{~min}$ at $400 \mathrm{rpm}$. After that $30 \mathrm{wt} \%$. composite was made in the form of dispersion. The deep coating method was used for this layer preparation. PET foil was used as a substrate. After drying the desired shape of antenna (Figure 1) was cut out.
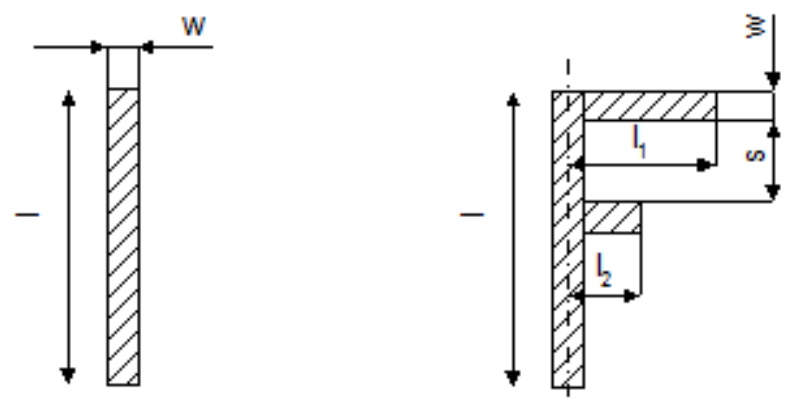

Figure 1. Topology and dimensions of the two studied antenna designs (on the left a dipole; on the right an F-antenna).

\subsection{Methods}

The scanning electron microscopy (SEM) observations were made using FEI Nova NanoSEM, scanning microscope (Waltham, MA USA). Sample was placed on SPI double side carbon tape substrates. All specimens were sputtered with gold/Pb before imaging to improve conductivity. After cryo-fractured in liquid nitrogen, the morphology of the failure surfaces (cross section) of PU/MWNT sample was observed.

The transmission electron microscopy (TEM) observations were made using TEM, JEOL Ltd., Tokyo, Japan microscope. The dispersions of the MWCNTs in acetone were cast on $\mathrm{Cu}$ grids.

The materials were also analyzed by X-ray photoelectron spectroscopy (XPS) on TFA XPS Physical Electronics instrument (Chanhassen, MN, USA) [28,29] at the base pressure in the chamber of about $6 \times 10^{-8} \mathrm{~Pa}$. The samples were excited with X-rays over a $400 \mu \mathrm{m}$ spot area with a monochromatic $\mathrm{Al}$ $\mathrm{K} \alpha 1,2$ radiations at $1486.6 \mathrm{eV}$. Photoelectrons were detected with a hemispherical analyzer positioned at an angle of $45^{\circ}$ with respect to the normal to the sample surface. Survey-scan spectra were made at 
a pass energy of $187.85 \mathrm{eV}$, the energy step was $0.4 \mathrm{eV}$. Individual high-resolution spectra for $\mathrm{C} 1 \mathrm{~s}$ were taken at a pass energy of 23.5 and $0.1 \mathrm{eV}$ energy step. The concentration of elements was determined from survey spectra by MultiPak v7.3.1 software from Physical Electronics (Chanhassen, MN, USA).

Thermogravimetrical (TGA) studies were performed on a TGA Q500 (TA instruments, New Castle, DE, USA). The analysis was made under following conditions: temperate range from 25 to $1000^{\circ} \mathrm{C}$ at $10^{\circ} \mathrm{C} / \mathrm{min}$ heating rate under nitrogen flow of $50 \mathrm{~mL} / \mathrm{min}$.

The conductivity of our composite material was measured on a $100 \mathrm{~mm}$ long and $10 \mathrm{~mm}$ wide sample made from polyethylene terephthalate (PET) substrate covered with a layer of PU/MWCNT composite. The composite and PET layers were 70 and $147 \mu \mathrm{m}$ thick, respectively. DC resistance was measured in two-point set-up using Fluke 867B graphical multimeter (Eindhoven, The Netherlands); with probes located at the ends of the sample strip — good reproducibility of conductivity measurement was achieved.

Measurement of material properties of composite materials is typically done with the use of rectangular waveguides [26,27]. To measure the effective conductivity and the effective permittivity of the studied PU/MWCNT composite firstly the samples were placed inside the rectangular waveguides. These measurements relied on our previous work described in [30]. In the second measurement set-up, the samples were placed between the flanges of the rectangular waveguides. Finally, the third measurement of the effective conductivity were conducted on a microstrip test circuit.

For the design of the dual band antenna, two topologies were chosen. The first one was in the form of a simple unipole while the second in the form of an F-shaped antenna [31]. Dimensions of both antennas' designs are shown in Figure 1. Basic measurements of the antennas were performed in the anechoic chamber using the EMC 32 measurement software from Rohde Schwarz (Munich, Germany). Measurements of reflection coefficient $S_{11}$ of antennas was done with the aid of the Keysight handheld spectrum analyzer N9912A (Santa Rosa, CA, USA) and with the Agilent vector network analyzer PNA-L-N5230A (Santa Rosa, CA, USA). The $S_{11}$ measurements were performed in the frequency range from 0.1 to $7 \mathrm{GHz}$. The initial dimensions of the antennas were optimized in CST microwave studio to achieve low $S_{11}$ over 2.45 and $5.18 \mathrm{GHz}$ bands. CST microwave studio is a commercial simulation software used for analysis of electromagnetic structures through solving the Maxwell equations via finite integration technique (FI). An active (radiating) part of the antenna was made of a composite comprising polyurethane filled with multiwall carbon nanotubes (PU/MWCNT).

\section{Results}

\subsection{Composite Material}

Scanning electron microscopy showed homogenous dispergation of multi wall carbon nanotubes in thermoplastic polyurethane as a matrix. The layer was made by simple dipping of the PET foil (the substrate) into the carbon nanotubes dispersion. The uniform layer was created during drying process, by which the solvent was removed. The morphology shows a significant amount of multiwall carbon nanotubes and the polyurethane part around them (Figure 2A). The cross section after cryo-fracture in liquid nitrogen (Figure 2B) shows uniform distribution of carbon nanotubes in vertical and horizontal direction. Another cross-section SEMs (Figure 2C) after cryo-fracture in liquid nitrogen confirms uniform thickness and also double side coating of the substrate by the composite layer. SEM micrograph can be also used for determination of the composite layer thickness (Figure 2D). 

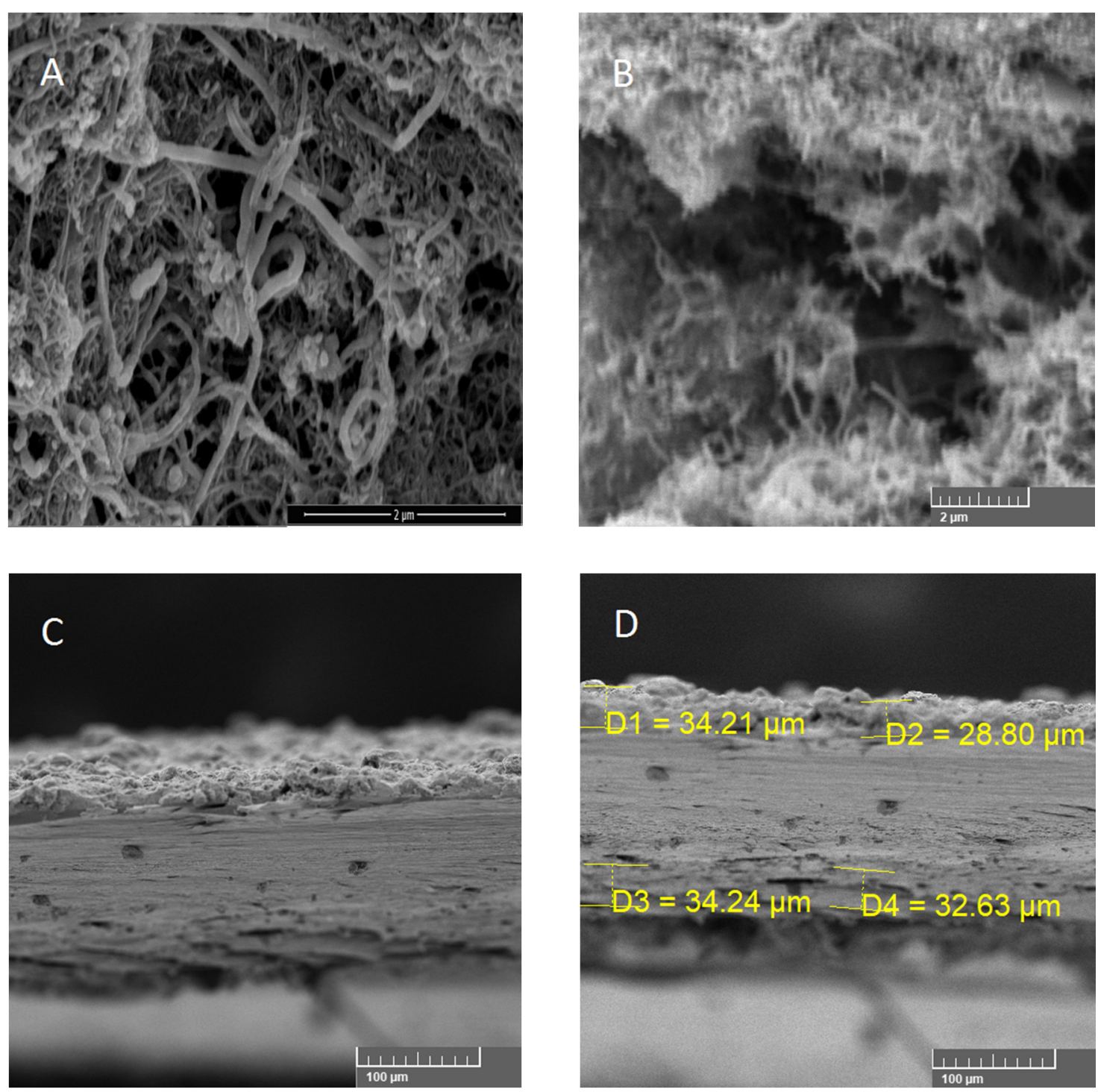

Figure 2. SEM pictures of prepared PU/MWCNT composite. (A) surface of PU/MWCNT composite. (B) cross section of prepared composite (upper part) (C) cross section of PU/MWCNT composite on PET foil. Double side coating. (D) Cross section of PU/MWCNT composite with measured thickness (denoted D1-D4).

Transmission electron microscopy was used to examine morphology of raw carbon nanotubes. The diameter of individual carbon nanotubes is around $25 \mathrm{~nm}$ and even the walls are distinguishable (Figure 3A). Carbon nanotubes have typical aggregate into bundles due to Van der Waals forces. To prevent this phenomenon, the sonication technique is used. Thus, macromolecular chains of PU are inserted between the carbon nanotubes to eliminate bundles formation. 

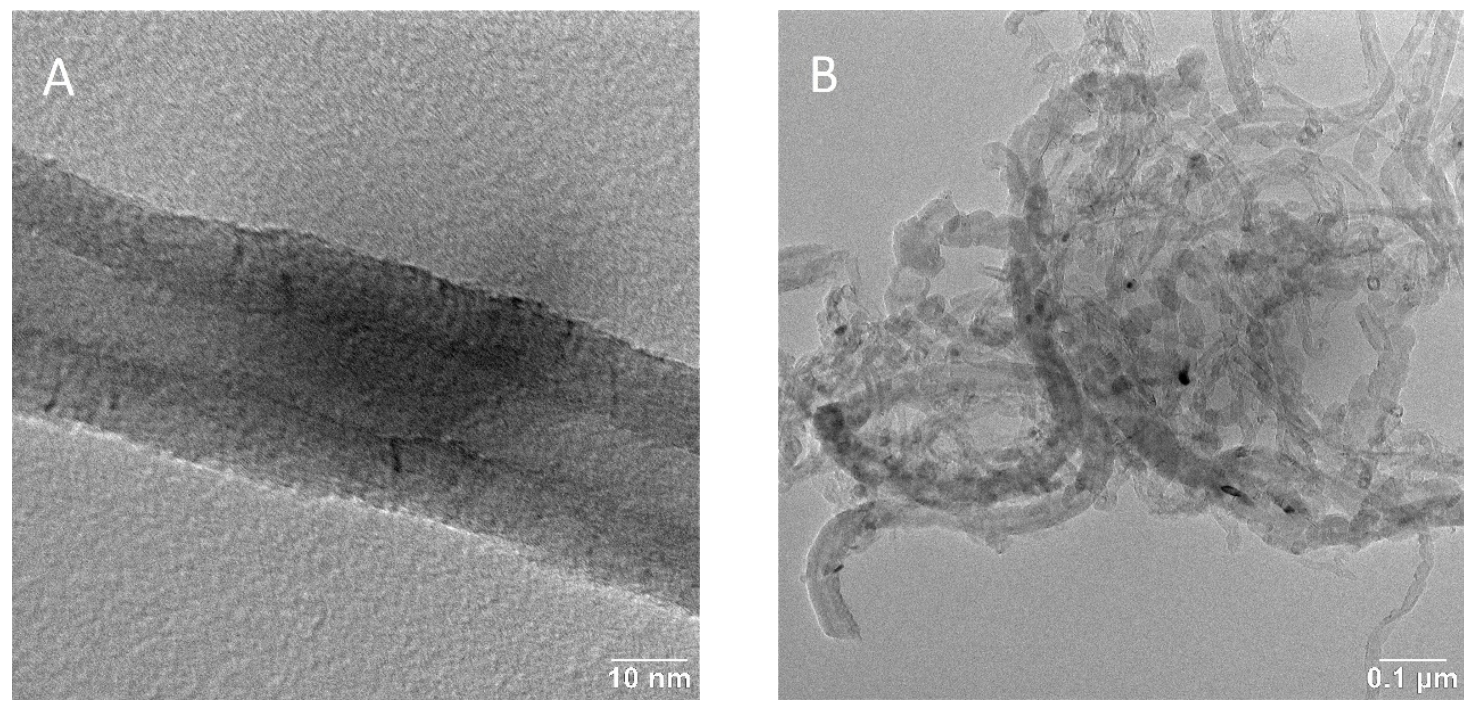

Figure 3. TEM picture of: (A) an individual multiwall carbon nanotube, (B) a bundle of multiwall carbon nanotubes.

The main binding energy peak $(284.5 \mathrm{eV})$ in XPS spectra of MWCNT was assigned to the C1s-sp ${ }^{2}$, while the other ones were assigned to $\mathrm{C}-\mathrm{O}(286.15 \mathrm{eV}), \mathrm{C}=\mathrm{O}(287.1 \mathrm{eV}), \mathrm{O}-\mathrm{C}=\mathrm{O}(288.8-289 \mathrm{eV})$ and C1s- $\pi-\pi^{*}(291.1-291.5 \mathrm{eV})$. According to our XPS results of MWCNT total oxygen content was determined to be 18.8 at $\%$ for pure MWCNT. The $\mathrm{sp}^{3} / \mathrm{sp}^{2}$ carbon ratios are 2.50 and 1.69 for pure MWCNT (Figure 4).

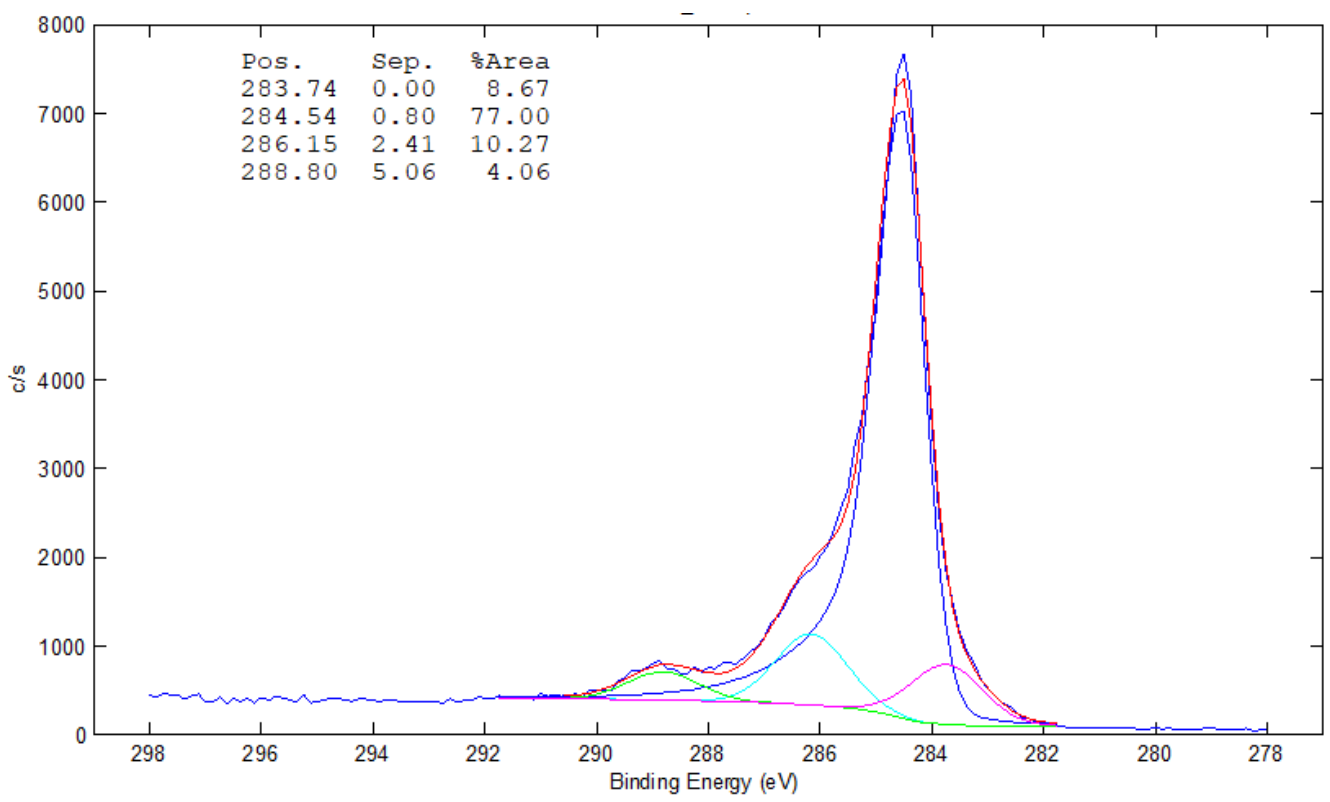

Figure 4. XPS analysis of MWCNT, raw material without any treatment.

Thermogravimetric curve presented in Figure 5 shows the weight loss during constant heating rate. Pure multiwall carbon nanotubes (MWCNT) show dramatic weight loss at 632 and $843^{\circ} \mathrm{C}$. Thermoplastic polyurethane (PU) has significant weight drop at $352{ }^{\circ} \mathrm{C}$. Polymer composite (PU/MWCNT) shows two slight weight drops at 313 and $365^{\circ} \mathrm{C}$, respectively, both of which corresponds to polyurethane decomposition; the cumulative drop is around $30 \mathrm{wt} \%$ and equals to polyurethane content of the PU/MWCNT composite. 


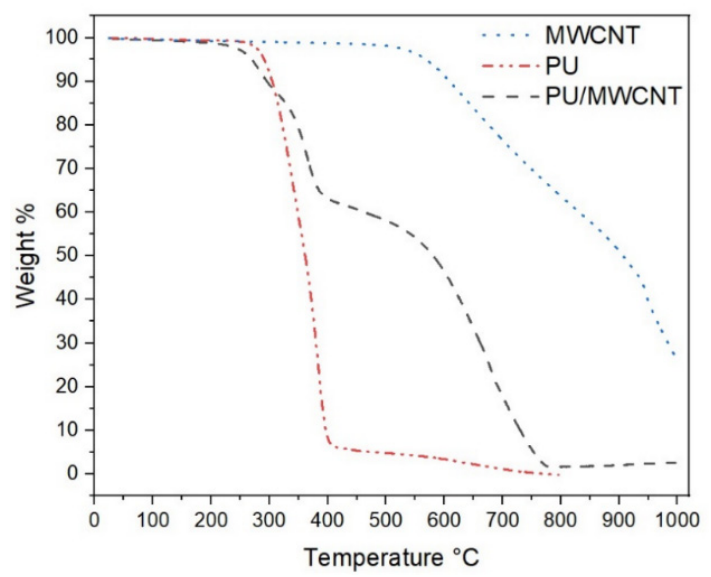

Figure 5. Thermogravimetric (TGA) curves of MWCNT (dot line), Thermoplastic polyurethane PU (dash dot dot line), PU/MWCNT composite (dash line).

The PU/MWCNT contains $30 \mathrm{wt} \%$ of multiwall carbon nanotubes. The height faction of conductive filler dramatically improves electrical conductivity which is crucial point to reach high radiation efficiency and gain of prepared antenna. Measurement of DC conductivity on concentrations of MWCNT is shown in Figure 6. The percolation happens for $20 \mathrm{wt} \%$ of MWCNT. For $23 \mathrm{wt} \%$ the conductivity around $0.3 \mathrm{~S} / \mathrm{m}$ was achieved. With increasing concentration of MWCNT above $23 \%$, the conductivity of the PU/MWCNT composite further increases. For concentration $30 \mathrm{wt} \%$, the conductivity $160 \mathrm{~S} / \mathrm{m}$ was achieved. This point is not shown in the graph for the case of clarity. Right part of the figure shows an impact of conductivity of the composite on radiation of a simple unipole antenna (length $24.9 \mathrm{~mm}$, width $4 \mathrm{~mm}, 0.5 \mathrm{~mm}$ thick Rogers RO4350B substrate). For conductivity $120 \mathrm{~S} / \mathrm{m}$, the radiation resistance of antenna at $2.45 \mathrm{GHz}$ around $30 \mathrm{Ohm}$ is obtained. However, for conductivity that is only $12 \mathrm{~S} / \mathrm{m}$, the radiation resistance becomes smaller (about $15 \mathrm{Ohms}$ ) and the gain of the unipole antenna is decreased. That is the reason why large filling of $30 \mathrm{wt} \%$ for our composite was used.
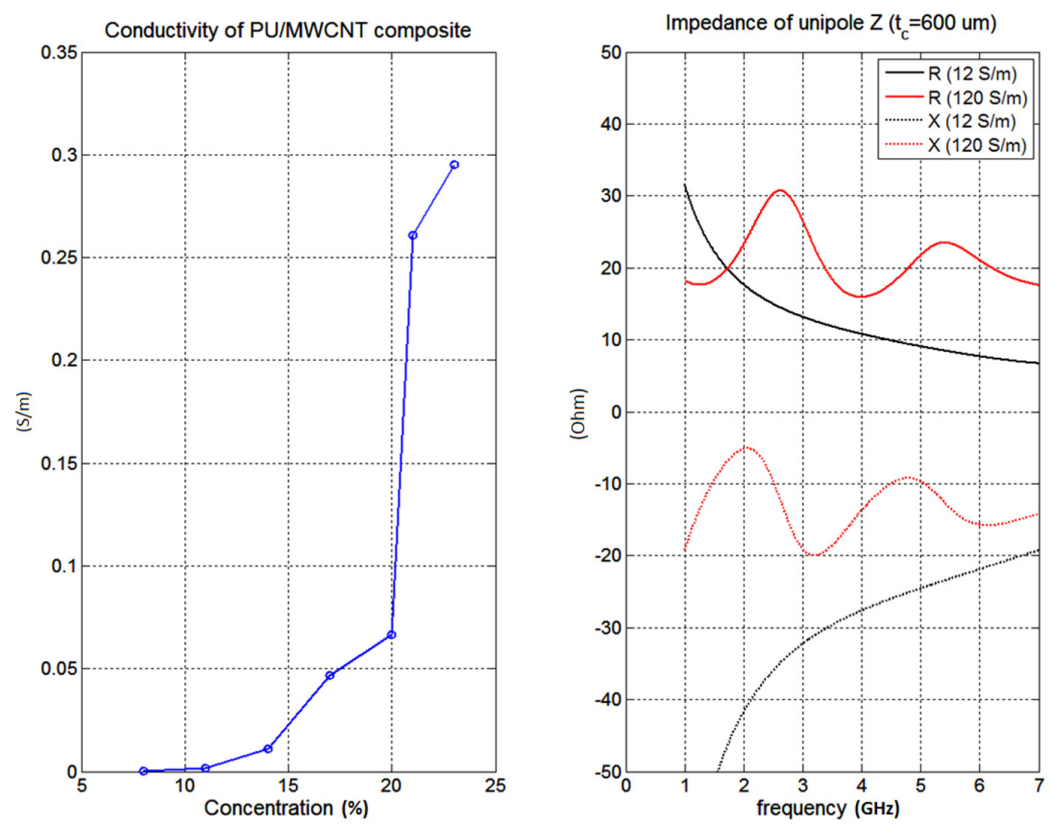

Figure 6. Left (Conductivity of PU/MWCNT composite versus concentration of CNTs), Right (Impedance of unipole antenna). 
Polymer composite antennas prepared on support substrate is a very novel idea. This fact makes it very difficult to compare with the literature. The inspiration was found on the opposite end of spectra of interest in electromagnetic shielding of GHz waves. There is no exception to use 45 or 50 wt $\%$ of conductive filler [32,33].

The highly filled system has some disadvantage which is necessary to solve. The chosen of dip coating technique is one of the easy ways how to prepare very uniform layer without defects. The DFM was chosen as a solvent for PU. PU solution in DMF has very low viscosity which allow to reach relatively high MWCNT content. PU solution also allow to control and adjust viscosity of PU/MWCNT and avoid mechanical degradation of used substrate, no abrasion was observed. SEM analysis also confirm on abrasion on the surface of prepared sample.

\subsection{Electrical Characterization}

Measured DC conductivity of the antenna $\sigma=160 \mathrm{~S} / \mathrm{m}$ was compared with AC conductivity extracted from waveguide measurements [30]. Despite the use of the conductive paste between the sample and the waveguide walls, the results were from measurements with the sample inside the waveguide were not acceptable. We believe that this was due to insufficient thickness of our material, which was only $70 \mu \mathrm{m}$ thick. On the other hand, results when measuring with samples sandwiched between the flanges were better. The DC measurements of conductivity were performed by a simple two-point method since the total resistance of the measured sample was much higher than a contact resistance.

The measured dependence of the relative permittivity $\left(\varepsilon_{\mathrm{r}}\right)$ and permeability $\left(\mu_{\mathrm{r}}\right)$ on frequency is shown in Figures 7 and 8. The real and imaginary part of permittivity of composites with CNTs is monotonically decreasing with frequency. This would be the case if the composite material was measured inside a rectangular waveguide [30]. However in our case, the measurement took place on the flange of the waveguide, but algorithms being used assumed that samples are placed inside the waveguide. This caused errors in the evaluation, which have two consequences. The first is that the functions $\varepsilon_{\mathrm{r}}$ and $\mu_{\mathrm{r}}$ do not decrease too much with frequency within a single waveguide band. The second consequence is that discontinuities arise on the curve when moving from one frequency band to another. Validity of the first and second statements (consequences) were verified by CST microwave studio, where a synthetic composite material having smooth $\varepsilon_{\mathrm{r}}$ and $\mu_{\mathrm{r}}$ was analyzed, resulting S-parameters were then transferred to MATLAB (Nattick, USA). Finally, $\varepsilon_{\mathrm{r}}$ and $\mu_{\mathrm{r}}$ were extracted by algorithm described in [30]. The results obtained in MATLAB confirmed both previous statements.
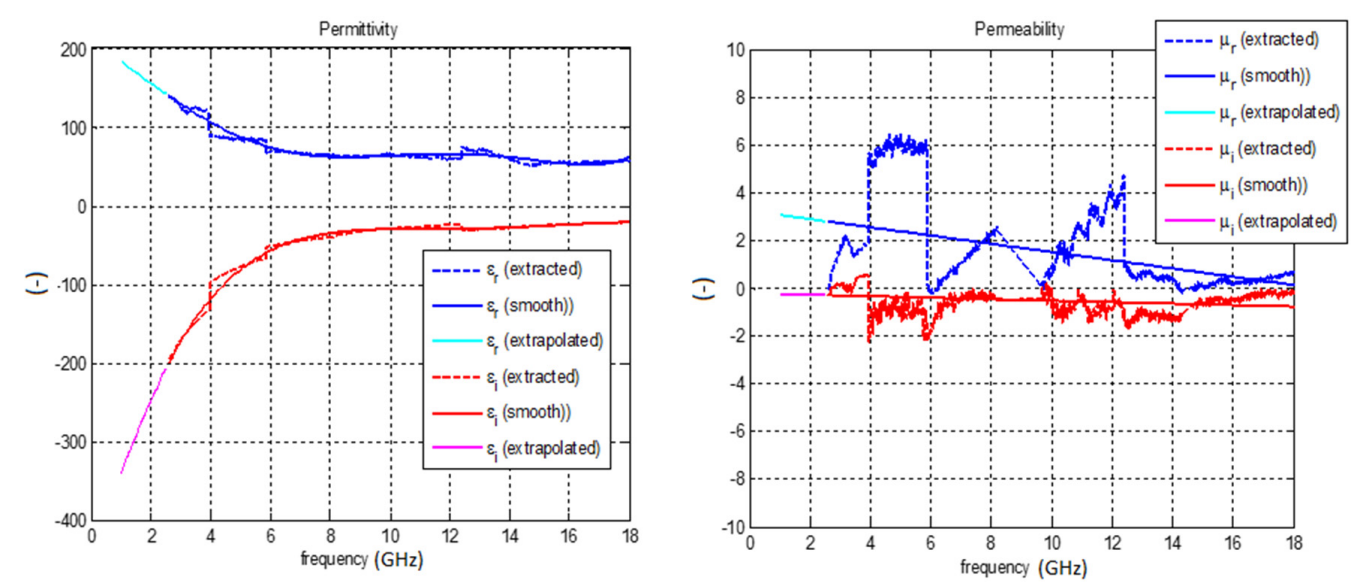

Figure 7. Measured effective permittivity (left) and magnetic permeability (right) of the polymer composite comprising carbon nanotubes and polymer matrix (measurement on the flange of the rectangular waveguide). 


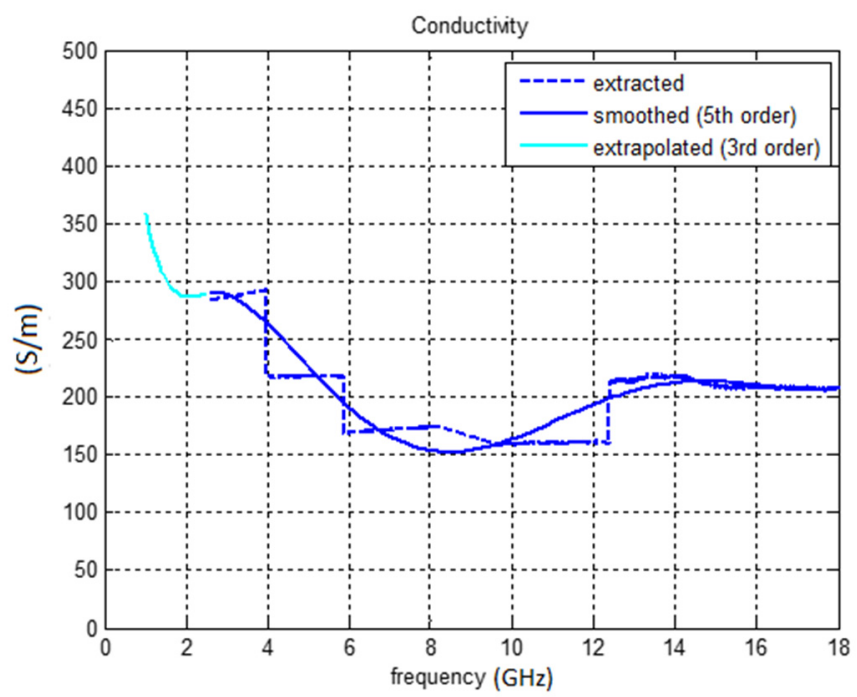

Figure 8. Measured effective conductivity of the polymer composite comprising carbon nanotubes and polymer matrix (measurement on the flange of the rectangular waveguide).

The average conductivity at $2.45 \mathrm{GHz}$ is about $290 \mathrm{~S} / \mathrm{m}$ and average conductivity at $5.18 \mathrm{GHz}$ is around $220 \mathrm{~S} / \mathrm{m}$ (Figure 8). The average permittivity at $2.45 \mathrm{GHz}$ is 130 and 90 at $5.18 \mathrm{GHz}$. The behavior of permeability could not be measured too accurately since a very thin $(70 \mu \mathrm{m})$ sample was used. The average value of the measured permeability was about 2.5 at $2.45 \mathrm{GHz}$ and it decreased with frequency. Since the PU/MWCNT composite material is non-magnetic, the values of permeability should be close to 1 .

Nevertheless, after the fabrication of a simple unipole composite based antenna (Rogers substrate RO4350B having thickness $h=0.508 \mathrm{~mm}$, unipole length $24.9 \mathrm{~mm}$ ), it was observed that the agreement between reflection coefficients of simulated and measured antenna was rather poor. The experimentally obtained values of $S_{11}$ in $\mathrm{dB}$ were approximately $2 \mathrm{~dB}$ higher than the value predicted by the full wave simulation program (CST microwave studio). This indicates that the real effective conductivity of the composite is smaller than the value measured on the flange of the waveguide.

Due to low precision of the waveguide methods (for thin samples), the conductivity of our composite at microwave frequencies was finally measured with a microstrip line (see Figure 9). After measurements of the insertion loss $S_{21}$ of the sample, the microstrip line was modelled in CST microwave studio (including SMA connectors) and the value of conductivity was changed by optimization in MATLAB to equal simulated and measured $S_{21}$ (see Figure 10). The resulting conductivity of our PU/MWCNT material was equal to $120 \mathrm{~S} / \mathrm{m}$. Assuming this value of conductivity the typical agreement between measured and simulated $S_{11}$ of a simple single layer unipole antenna improved from 2.0 to $0.5 \mathrm{~dB}$.
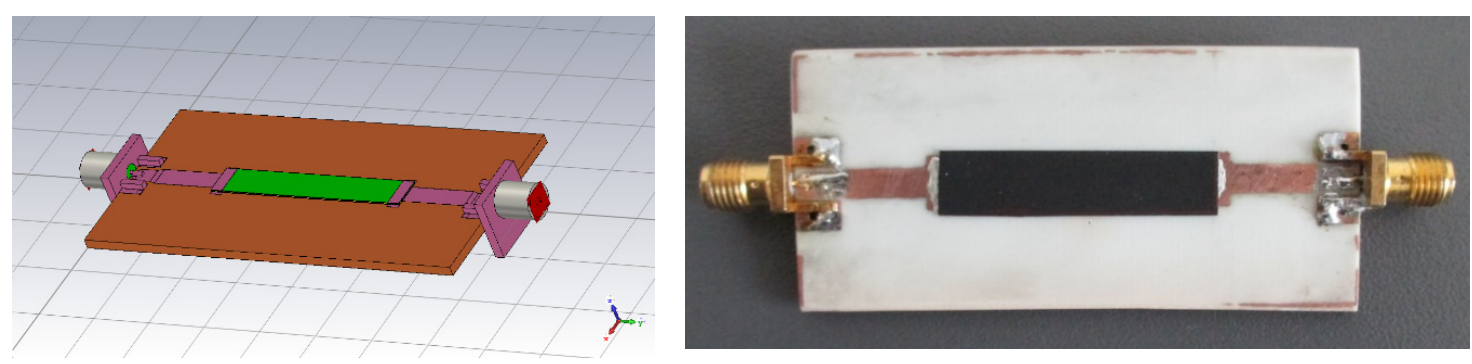

Figure 9. CST studio model of (left) and the real microstrip line (right) made from polymer composite comprising carbon nanotubes and polymer matrix for effective conductivity measurement. 


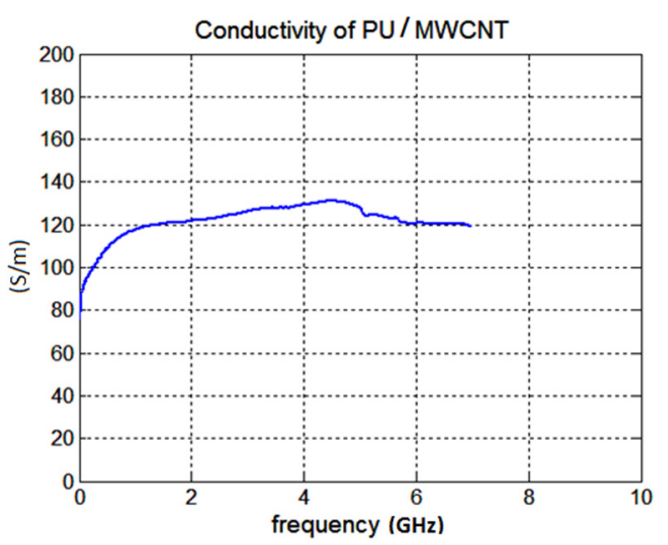

Figure 10. Measured results of the effective conductivity of the PU/MWCNT composite by a microstrip line.

\subsection{Design of Antenna}

In the case of the design of a grounded unipole antenna printed on a traditional dielectric substrate, the thickness of the antenna (substrate) must be considerable in order to obtain reasonable radiation resistance of the antenna. In the case of PU/MWCNT (or other carbon-based antennas such as buckypaper or PANI/MWCNT), the thickness can be smaller. Thus, low profile antennas can be realized. In Figure 11 a parametric study, performed in CST microwave studio, of a simple unipole made from PU/MWCNT composite is shown. The simulations considered that the unipole is placed on $0.508 \mathrm{~mm}$ thick Rogers RO4350B substrate. The length of unipole was $24.9 \mathrm{~mm}$ and width $4 \mathrm{~mm}$. It can be seen that with increasing conductivity of the composite radiation resistance increases too; also, the reactance of the antenna starts to oscillate as is typical of antennas made from conductors.
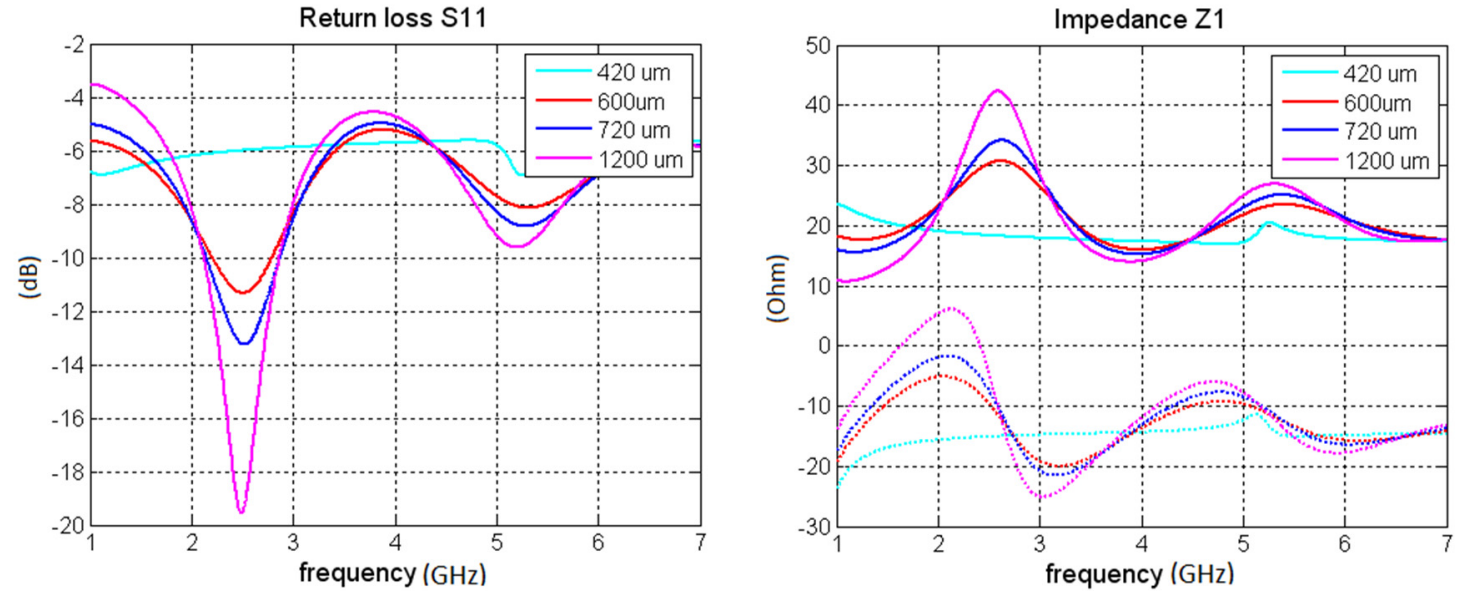

Figure 11. A simulation of characteristics of a unipole made from PU/MWCNT, input impedance as a function of conductivity.

In order to make the antenna operable and to achieve practical radiation efficiency a relatively thick composite layer ( $t_{c}$ layer) has to be used. Considering conductivity around $120 \mathrm{~S} / \mathrm{m}$ for our operating bands, at least $600 \mu \mathrm{m}$ thick composite has to be used. However, preparation of such a thick composite layer was not feasible from a technological point of view. Therefore, the antenna was made by stacking three layers on top of each other (Figure 12). Assuming the total thickness of the antenna $t_{\mathrm{c}}=600 \mu \mathrm{m}$, the radiation resistance of the antenna of about $30 \mathrm{Ohm}$ was achieved. With further thickness or conductivity increase, radiation resistance upwards of $50 \mathrm{Ohm}$ is achievable. However, the fabrication of an antenna consisting of more than three layers would be technologically problematic. 


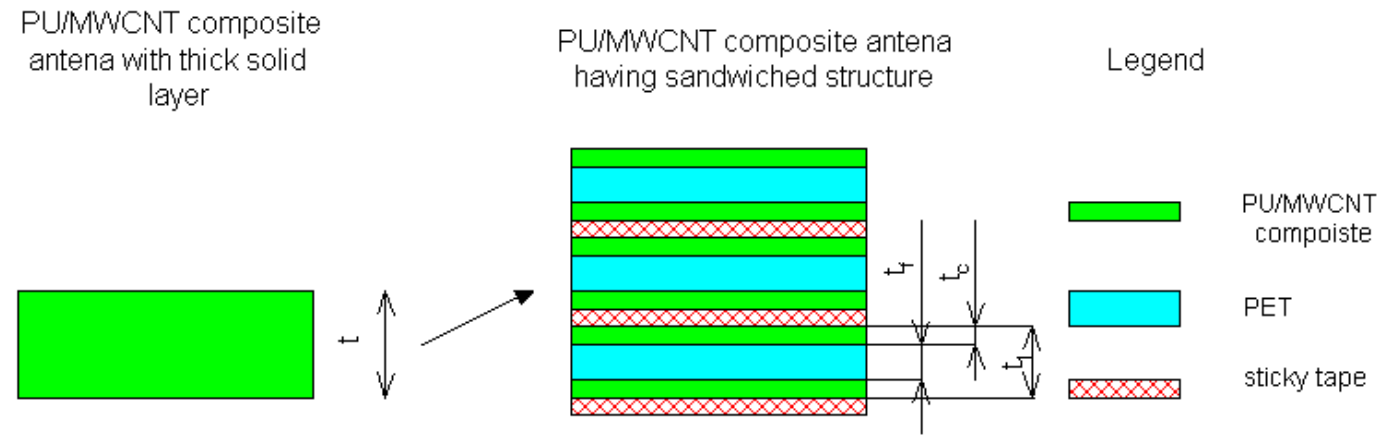

Figure 12. Detailed view of the layered structure of the polymer antenna.

Matching of the unipole antenna can be done with a LC matching circuit (Figure 13). Either a simple LC match or a double LC can be used. Use of the double LC match can guarantee independent matching in both operating bands. For the purpose of simplicity, the simple LC match was used for the unipole antenna. The length and width of $C$ was 8 and $7 \mathrm{~mm}$ respectively. The length and width of $L$ was 2.0 and $1.9 \mathrm{~mm}$ respectively.
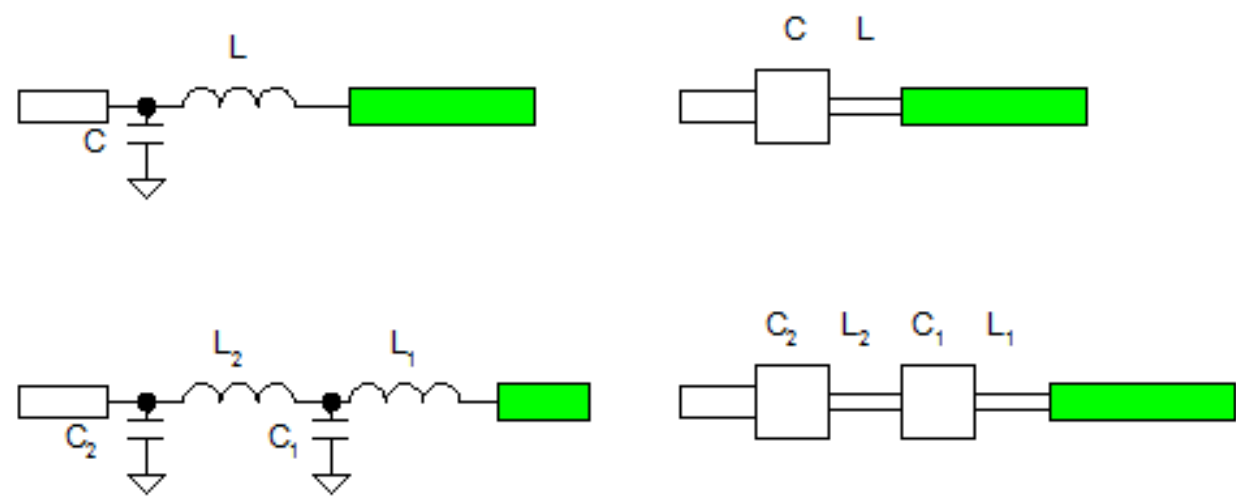

Figure 13. Schematic of the matching circuit of the antenna (top: unipole, simple match, bottom: independent matching in both operating bands).

\subsection{Fullwave Simulations of the Antenna and Measurements}

Based on the procedure described in the previous chapter, a unipole and an F-antenna were designed for dual band operation at 2.45 and $5.18 \mathrm{GHz}$ frequency bands. The design with the F-antenna was inspired by the paper [31]. The difference between our approach and the approach described in [31] is that our design uses a ground plane. The presence of the ground plane is essential for the practical design of antenna for wearable applications.

The carrier substrate of the antennas was $2 \mathrm{~mm}$ thick polypropylene. The large thickness was essential in order to secure practical values of antennas' gain.

The 3D models of the antennas are shown in Figure 14. Both antennas (for dimensions see Table 1) are realized by a sandwiching technique. The dimensions of the substrate ( $2 \mathrm{~mm}$ PP layer) are $50 \mathrm{~mm}$ $\times 70 \mathrm{~mm}$. The antennas were fed by a microstrip port. The reference plane of the port was placed at the beginning of the antenna. The effective permittivity of the PU/MWCNT composite was the same as given in Figure 7. The value of the effective permittivity is smoothly decreasing with frequency. The numerical value of the permittivity was 180 at $1 \mathrm{GHz}$ and 70 at $7 \mathrm{GHz}$. The effective conductivity was constant and equal to $120 \mathrm{~S} / \mathrm{m}$. The permeability of 1 was assumed for the PU/MWCNT material. 

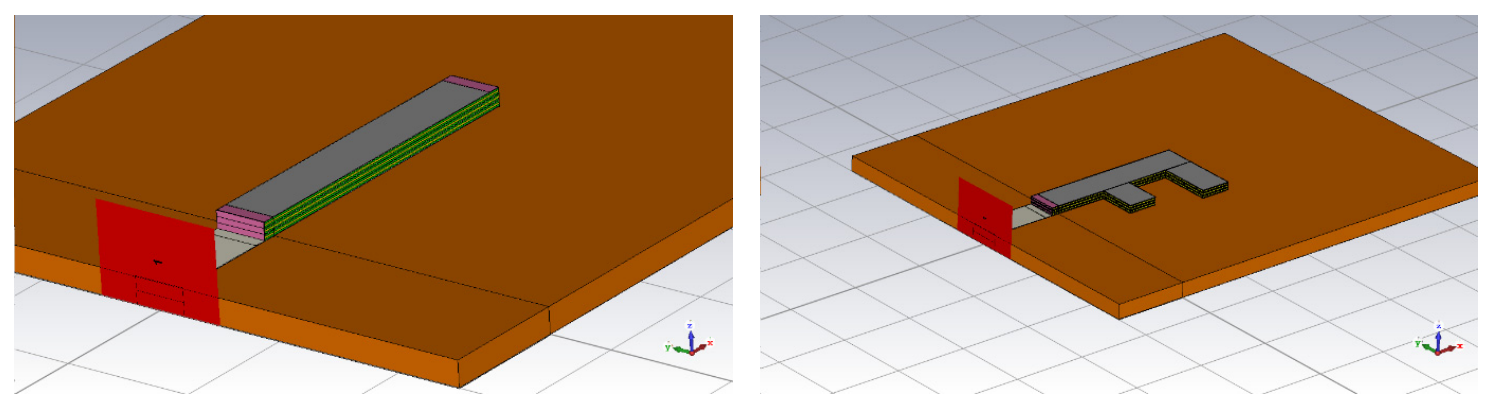

Figure 14. 3D model of unipole and F-antenna in CST microwave studio.

Table 1. Physical dimensions of the unipole and the F-antenna.

\begin{tabular}{cccc}
\hline Antenna Type & Parameter & Symbol & Numerical Value \\
\hline \multirow{4}{*}{ Unipole } & length of unipole & $l(\mathrm{~mm})$ & 26 \\
& width of unipole & $w(\mathrm{~mm})$ & 4 \\
& total thickness of unipole (including PET layers) & $t_{\mathrm{c}}(\mu \mathrm{m})$ & 120 \\
& $t_{\text {tot }}(\mu \mathrm{m})$ & 1014 \\
\hline \multirow{4}{*}{ F-antenna } & length of F-antenna & $l(\mathrm{~mm})$ & 21 \\
& length of first arm & $l_{1}(\mathrm{~mm})$ & 11 \\
& length of second arm & $l_{2}(\mathrm{~mm})$ & 7 \\
& width of F-antenna & $w(\mathrm{~mm})$ & 4 \\
& separation between arms & $s(\mathrm{~mm})$ & 5.9 \\
& thickness of single composite layer & $t_{\mathrm{c}}(\mu \mathrm{m})$ & 70 \\
& total thickness of F-antenna (including PET layers) & $t_{\text {tot }}(\mu \mathrm{m})$ & 714 \\
\hline
\end{tabular}

The unipole and the F-antenna were manufactured in our laboratory (see Figure 15). The feeding of our antennas was realized by a short $50 \Omega$ section on the PP substrate and the $18 \mathrm{~mm}$ long $50 \Omega$ section on the FR4 substrate. The microstrip line and the ground layer of PP material was realized by $35 \mu \mathrm{m}$ thick copper foil. The foil had a self-adhesive acrylic material. Electrical connection between microstrip lines on PP layer and microstrip line on the FR4 substrate was performed by a conductive silver compound. The same compound was also used for connection of PU/MWCNT composite with the feeding microstrip. The unipole antenna contained also a simple LC matching circuit to improve $S_{11}$ of the antenna. The F-antenna does not use the matching since the $50 \Omega$ impedance can be achieved by selection of proper dimensions $l, l_{1}$ and $l_{2}$ of the antenna.
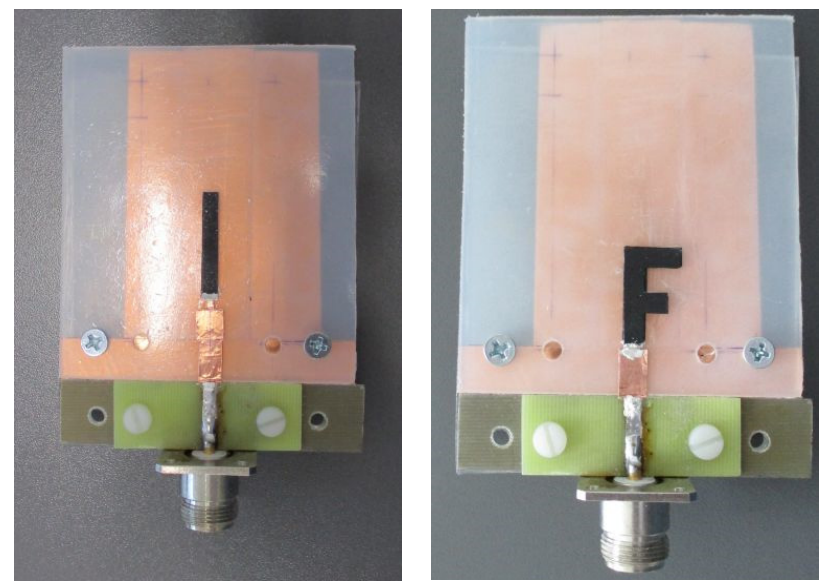

Figure 15. A photo of manufactured antennas (left: unipole; right: F-antenna). 
Properties of the manufactured antenna were further examined in detail in our EMC laboratory. Firstly, the $S_{11}$ of the antennas was measured and compared with simulations (see Figure 16). For the unipole a very good agreement between measured and simulated $S_{11}$ was obtained inside $2.45 \mathrm{GHz}$ operating band. At the $5.18 \mathrm{GHz}$ the measured $S_{11}$ resonates at lower frequency than the frequency predicted by simulation. For the F-antenna, correlation between measured and simulated $S_{11}$ became worse but the manufactured F-antenna showed an excellent impedance match in both operating bands.
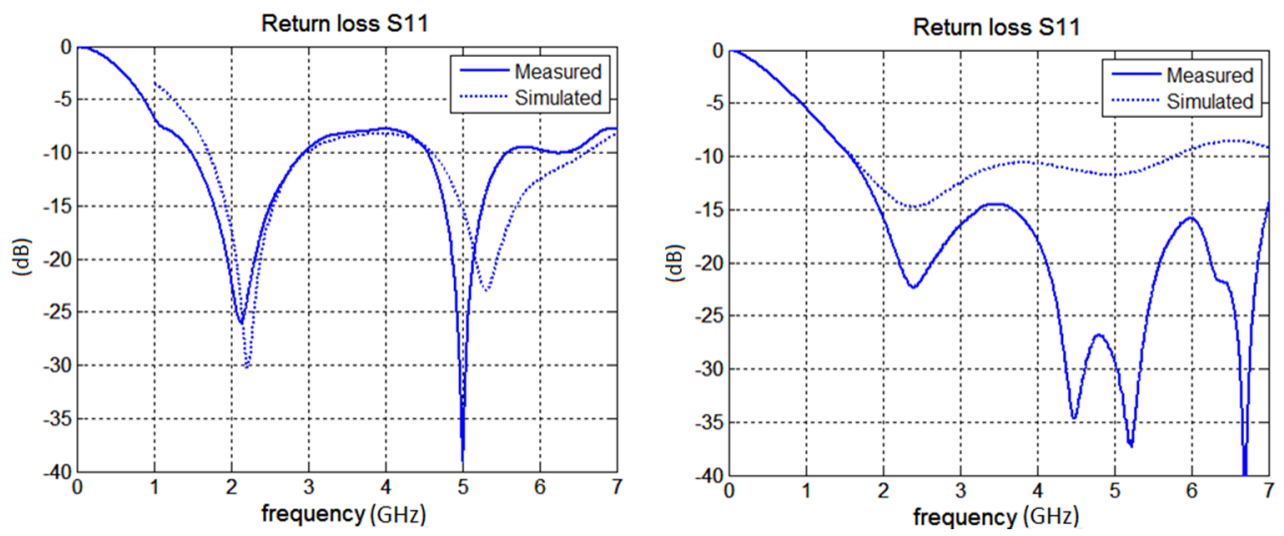

Figure 16. The measured and simualted return loss of antenna (unipole on the left; F-antenna on the right).

Secondly, radiation properties of both antennas were measured in an anechoic chamber (see Figures 17 and 18). The measured gain at the direction of main lobe is about 2 dBi larger than the gain predicted by CST. This is mainly attributed to the fact, that the model of the antennas in CST did not contained feeding microstrip on FR4 line, impedance matching circuit and the $\mathrm{N}$-connector.
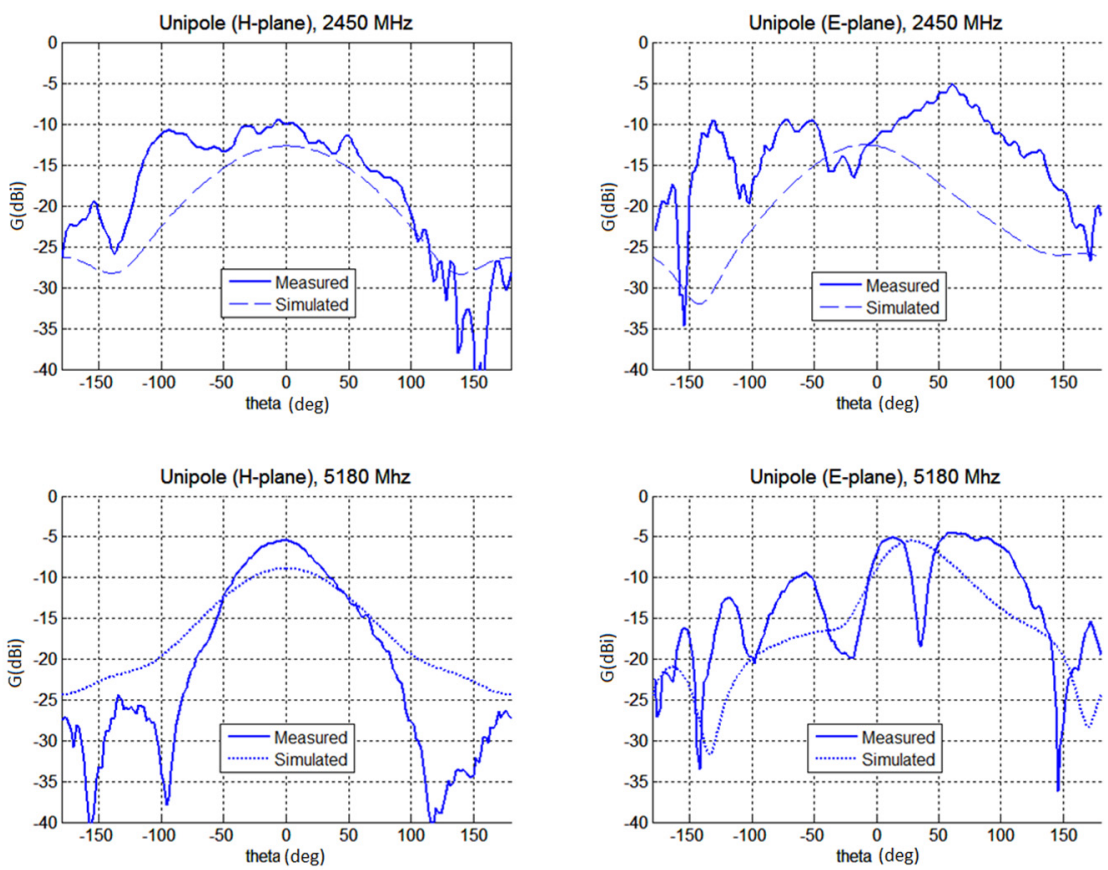

Figure 17. The measured and simualted gain of the unipole antenna (top line, absolute gain for $\mathrm{H}$ and E-plane at $2450 \mathrm{MHz}$, bottom line, absolute gain for $\mathrm{H}$ and E-plane for $5180 \mathrm{MHz}$ ). 

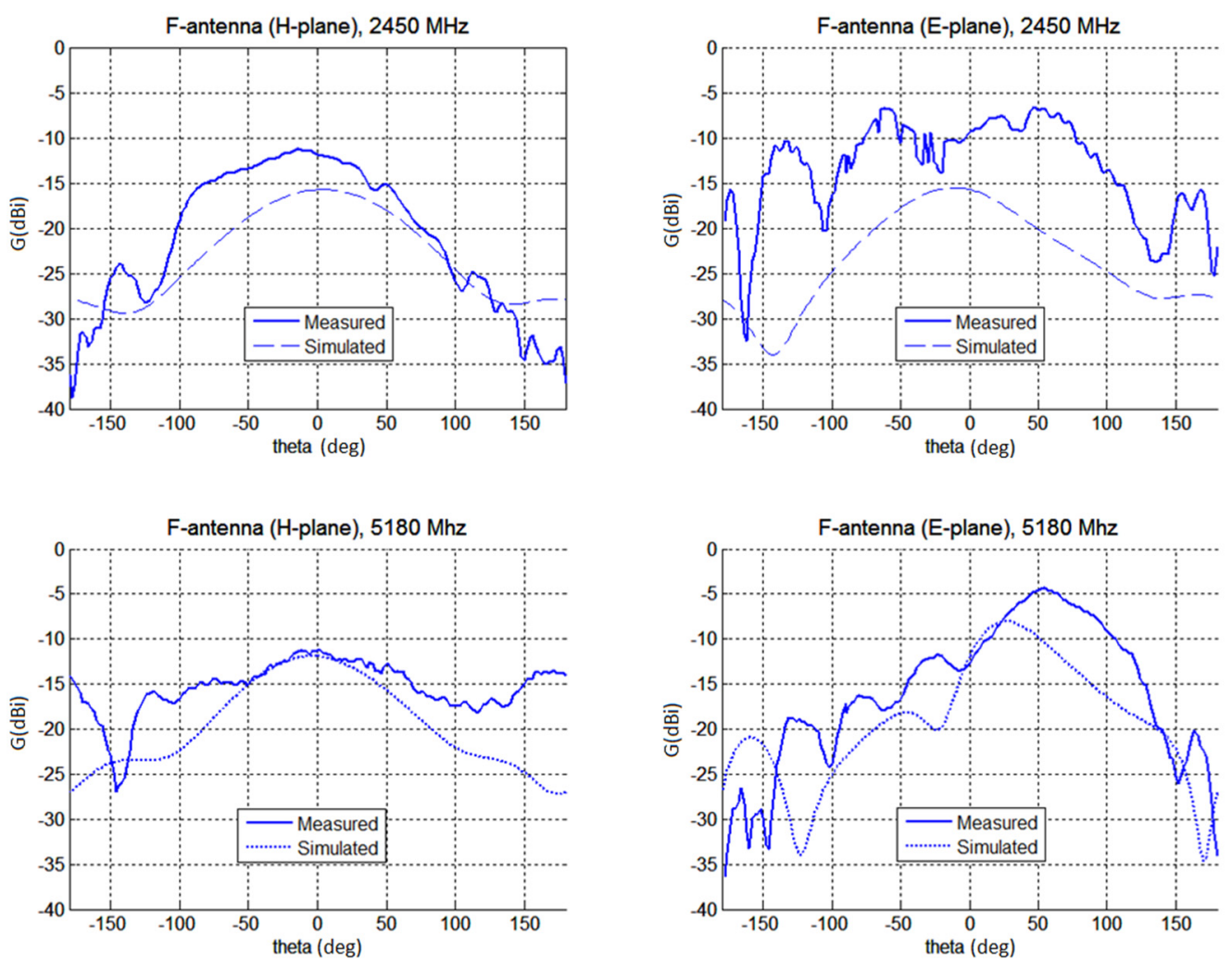

Figure 18. The measured and simulated gain of the F-antenna (top line, absolute gain for $\mathrm{H}$ and E-plane at $2450 \mathrm{MHz}$, bottom line, absolute gain for $\mathrm{H}$ and E-plane for $5180 \mathrm{MHz}$ ).

It was observed that both antennas achieved a very good match for both operating bands. The correlation between measured $S_{11}$ and simulated $S_{11}$ is also quite good.

The agreement of predicted and simulated radiation patterns is not as good as expected. The comparison of measured and simulated gains is given in Table 2. In general, the measured gain was by about $2 \mathrm{~dB}$ larger than the simulated values. We mainly attribute this to the fact, that simulation in CST have not assumed feeding by the microstrip on the FR substrate. The model of the antenna in CST does not account for the presence of the $\mathrm{N}$ panel connector.

Table 2. Simulated and measured gain of dipole and F-antenna.

\begin{tabular}{ccccc}
\hline Antenna Type & $\begin{array}{c}\text { Frequency } \\
\text { (MHz) }\end{array}$ & $\begin{array}{c}\text { Simulated Gain } \\
\mathbf{( d B i )}\end{array}$ & $\begin{array}{c}\text { Measured Gain } \\
(\mathbf{d B i})\end{array}$ & $\begin{array}{c}\text { Simulated } \\
\text { Radiation Efficiency } \\
(\%)\end{array}$ \\
\hline \multirow{2}{*}{ Unipole } & 2450 & -12.7 & -10.0 & 3.6 \\
& 5180 & -8.9 & -5.5 & 6.8 \\
\hline \multirow{2}{*}{ F-antenna } & 2450 & -15.8 & -12.0 & 2.2 \\
& 5180 & -11.9 & -11.4 & 4.0 \\
\hline
\end{tabular}

The maximum measured gain of the unipole is $-10 \mathrm{dBi}$ and $-5.5 \mathrm{~dB}$ for 2.45 and $5.18 \mathrm{GHz}$, respectively. The gain of the F-antenna is smaller since it used a thinner composite layer $\left(t_{\mathrm{c}}=70 \mu \mathrm{m}\right.$ only compared to $t_{\mathrm{c}}=120 \mu \mathrm{m}$ for the unipole). Its gain is about $-12 \mathrm{dBi}$ at $2.45 \mathrm{GHz}$ and $-11.4 \mathrm{dBi}$ at $5.18 \mathrm{GHz}$. By using thickness $t_{\mathrm{c}}=120 \mu \mathrm{m}$ for F-antenna the gain would increase about $2 \mathrm{dBi}$.

Except of the gain, the radiation efficiency of the designed antennas was also monitored (Table 2). The unipole antenna $\left(t_{\mathrm{c}}=600 \mu \mathrm{m}\right)$ had radiation efficiency 3.6 and 6.8 percent for both operating bands. The radiation efficiency of the F-antenna was smaller due to a smaller thickness of the F-antenna $\left(t_{\mathrm{c}}=420 \mu \mathrm{m}\right)$. 


\section{Conclusions}

A dual band ( 2.45 and $5.18 \mathrm{GHz}$ ) polymer composite based antenna has been designed and characterized. The antenna is made of a composite comprising polyurethane filled with multiwall carbon nanotubes (PU/MWCNT). Main benefit of used composite material is relative simplicity of its synthesis. Second benefit is flexibility of radiator of prepared antenna.

Although the absolute DC conductivity of the composite is lower $(\sigma=160 \mathrm{~S} / \mathrm{m})$ than for PPy or PEDOT it is still applicable for antenna design. In order to achieve the practical efficiency of radiation and to obtain practical gain the antenna, it is necessary to realize the antennas by means of thick layers.

Using the PU/MWCNT composite, a unipole and dual-band F-antenna on a $2 \mathrm{~mm}$ polypropylene (PP) substrate was designed and manufactured.

Measured gain of the unipole antenna is -10.0 and $-5.5 \mathrm{dBi}$ for 2.45 and $5.18 \mathrm{GHz}$ frequency bands, The gain of F-antenna is lower than the gain of the unipole since the smaller thickness of the PU/MCNWT composite was used for the F-antenna than the thickness of the composite for the unipole. The gain of the unipole and F-antenna predicted by CST microwave studio did not agreed to much with the measured gains. This is mainly attributed to the fact, that the radiation effect of FR4 microstrip feeding line and the radiation effect of $\mathrm{N}$-connector were not modeled in CST microwave studio.

In addition to the gain, the agreement of the reflection coefficient $S_{11}$ of both antennas obtained by measurement and simulation was also monitored. A good agreement was reached for the unipole. This good agreement was caused by a precise measurement of conductivity of the PU-MWCNT composite at microwave frequencies up to $7 \mathrm{GHz}$.

The designed antennas are partially bendable and might be practically used in wearable applications. The proposed PU/MWCNT composite material can also find application in other areas than antenna design. For example microstrip matches (terminations), attenuators, as a resistive element in periodic frequency selective surfaces etc.

Author Contributions: R.O., S.G. and P.S. have been responsible for conceptual planning and writing of the paper. S.G., R.M., J.M. and R.D. have done simulations, experiments and processing of measurement data. All authors have read and agreed to the published version of the manuscript.

Funding: This work was supported by the Ministry of Education, Youth and Sports of the Czech Republic-DKRVO (RP/CPS/2020/006) and the national budget of the Czech Republic, within the framework of the project CPS-strengthening research capacity (reg. number: CZ.1.05/2.1.00/19.0409).

Conflicts of Interest: The authors declare no conflict of interest.

\section{References}

1. Qiu, Q.; Zhu, M.; Li, Z.; Qiu, K.; Liu, X.; Yu, J.; Ding, B. Highly flexible, breathable, tailorable and washable power generation fabrics for wearable electronics. Nano Energy 2019, 58, 750-758. [CrossRef]

2. Zamarayeva, A.M.; Ostfeld, A.E.; Wang, M.; Duey, J.K.; Deckman, I.; Lechêne, B.P.; Davies, G.; Steingart, D.A.; Arias, A.C. Flexible and stretchable power sources for wearable electronics. Sci. Adv. 2017, 3, e1602051. [CrossRef] [PubMed]

3. Andreu-Perez, J.; Leff, D.R.; Ip, H.M.D.; Yang, G.-Z. From Wearable Sensors to Smart Implants-Toward Pervasive and Personalized Healthcare. IEEE Trans. Biomed. Eng. 2015, 62, 2750-2762. [CrossRef] [PubMed]

4. Zhu, Z.; Liu, T.; Li, G.; Li, T.; Inoue, Y. Wearable Sensor Systems for Infants. Sensors 2015, 15, 3721-3749. [CrossRef] [PubMed]

5. Trung, T.Q.; Lee, N. Flexible and Stretchable Physical Sensor Integrated Platforms for Wearable Human-Activity Monitoringand Personal Healthcare. Adv. Mater. 2016, 28, 4338-4372. [CrossRef]

6. Parrilla, M.; Cánovas, R.; Jeerapan, I.; Andrade, F.J.; Wang, J. A Textile-Based Stretchable Multi-Ion Potentiometric Sensor. Adv. Health Mater. 2016, 5, 996-1001. [CrossRef] [PubMed]

7. Ponomarenko, A.T.; Shevchenko, V.G.; Enikolopyan, N.S. Formation processes and properties of conducting polymer composites. Adv. Polym. Sci. 1990, 96, 125-147. [CrossRef]

8. Locher, I.; Klemm, M.; Kirstein, T.; Troster, G. Design and Characterization of Purely Textile Patch Antennas. IEEE Trans. Adv. Packag. 2006, 29, 777-788. [CrossRef] 
9. Salvado, L.; Loss, C.; Gonçalves, R.; Pinho, P. Textile Materials for the Design of Wearable Antennas: A Survey. Sensors 2012, 12, 15841-15857. [CrossRef]

10. Rmili, H.; Miane, J.-L.; Zangar, H.; Olinga, T. Design of microstrip-fed proximity-coupled conducting-polymer patch antenna. Microw. Opt. Technol. Lett. 2006, 48, 655-660. [CrossRef]

11. Matyas, J.; Olejnik, R.; Slobodian, P. Flexible microstrip antenna based on carbon nanotubes/(ethylene-octene copolymer) thin composite layer deposited on PET substrate. In Proceedings of the 6th International Conference on Materials and Applications for Sensors and Transducers, Athens, Greece, 27-30 September 2017; Volume 939.

12. Olejnik, R.; Slobodian, P.; Matyas, J.; Babar, D.G. High elastic polyurethane/carbon nanotube composite laminate for structure health monitoring by gain shifting of antenna sensing element. In Proceedings of the 5th International Conference on Materials and Applications for Sensors and Transducers, Mykonos, Greece, 27-30 September 2015; Volume 108.

13. Matyas, J.; Munster, L.; Olejnik, R.; Vlcek, K.; Slobodian, P.; Krcmar, P.; Urbanek, P.; Kuritka, I. Antenna of silver nanoparticles mounted on a flexible polymer substrate constructed using inkjet print technology. Jpn. J. Appl. Phys. 2016, 55, 02BB13. [CrossRef]

14. Matyas, J.; Slobodian, P.; Munster, L.; Olejnik, R.; Urbanek, P. Microstrip antenna from silver nanoparticles printed on a flexible polymer substrate. Mater. Today Proc. 2017, 4, 5030-5038. [CrossRef]

15. Hamouda, Z.; Wojkiewicz, J.-L.; Pud, A.; Belaabed, B.; Bergheul, S.; Lasri, T. Polyaniline-carbon nanotubes composites Based patch antenna. In Proceedings of the 8th European Conference on Antennas and Propagation, The Hague, The Netherlands, 6-11 April 2014; p. 2197.

16. Hamouda, Z.; Wojkiewicz, J.-L.; Pud, A.; Kone, L.; Belaabed, B.; Bergheul, S.; Lasri, T. Dual-Band Elliptical Planar Conductive Polymer Antenna Printed on a Flexible Substrate. IEEE Trans. Antennas Propag. 2015, 63, 5864-5867. [CrossRef]

17. Verma, A.; Fumeaux, C.; Truong, V.T.; Bates, B.D. A 2 GHz Polypyrrole Microstrip Patch Antenna on Plexiglas (TM) Substrate. In Proceedings of the 2009 Asia Pacific Microwave Conference, Singapore, 7-10 December $2009 ;$ p. 36.

18. Chen, S.J.; Fumeaux, C.; Talemi, P.; Chivers, B.; Shepherd, R. Progress in conductive polymer antennas based on free-standing polypyrrole and PEDOT: PSS. In Proceedings of the 2016 17th International Symposium on Antenna Technology and Applied Electromagnetics, Montreal, QC, Canada, 10-13 July 2016.

19. Kaufmann, T.; Shepherd, R.; Fumeaux, C. Modeling Conductive Polymer Antennas in the Microwave Region. In Proceedings of the 2012 IEEE International Conference on Wireless Information Technology and Systems (ICWITS), Maui, HI, USA, 11-16 November 2012; pp. 1-4.

20. Wang, Y.; Wang, T.; Wang, T.; Zhang, J.; Chen, J.; Yang, R.; Ruan, L.; Wang, B. Facile preparation of multifunctional poly(amide-imide)/polyaniline films: Combining self-cleaning, self-extinguishing, and conductive. Polym. Eng. Sci. 2019, 59, 33-43. [CrossRef]

21. Wang, Y.; Yu, H.; Li, Y.; Wang, T.; Xu, T.; Chen, J.; Fan, Z.; Wang, Y.; Wang, B. Facile Preparation of Highly Conductive Poly(amide-imide) Composite Films beyond $1000 \mathrm{~S}$ m-1 through Ternary Blend Strategy. Polymers 2019, 11, 546. [CrossRef] [PubMed]

22. Mehdipour, A.; Sebak, A.-R.; Trueman, C.W.; Rosca, I.D.; Hoa, S.V. Reinforced Continuous Carbon-Fiber Composites Using Multi-Wall Carbon Nanotubes for Wideband Antenna Applications. IEEE Trans. Antennas Propag. 2010, 58, 2451-2456. [CrossRef]

23. Mehdipour, A.; Rosca, I.D.; Sebak, A.-R.; Trueman, C.W.; Hoa, S.V. Carbon Nanotube Composites for Wideband Millimeter-Wave Antenna Applications. IEEE Trans. Antennas Propag. 2011, 59, 3572-3578. [CrossRef]

24. Braun, H.P.; Perini, S.; Lanagan, M.T. Measurement of the surface resistivity and electrical conductivity of carbon nanotube sheets using the resonant post-method. Mater. Lett. 2016, 167, 297-299. [CrossRef]

25. Wang, Y.; Chen, J.; Shen, Y.; Wang, T.; Ni, Y.; Zhang, Z.; Sun, L.; Ji, B.; Wang, B. Control of Conductive and Mechanical Performances of Poly(Amide-Imide) Composite Films Utilizing Synergistic Effect of Polyaniline and Multi-Walled Carbon Nanotube. Polym. Eng. Sci. 2018, 59, 224-230. [CrossRef]

26. Al Moayed, N.N.; Khan, U.; Obol, M.; Gupta, S.; Afsar, M.N. Characterization of Single- and Multi-walled NCarbon Nanotubes at Microwave Frequencies. In Proceedings of the 2007 IEEE Instrumentation \& Measurement Technology Conference, Warsaw, Poland, 1-3 May 2007; Volume 1, p. 1951. 
27. Challa, R.K.; Kajfez, D.; Demir, V.; Gladden, J.R.; Elsherbeni, A.Z. Characterization of Multiwalled Carbon Nanotube (MWCNT) Composites in a Waveguide of Square Cross Section. IEEE Microw. Wirel. Components Lett. 2008, 18, 161-163. [CrossRef]

28. Cvelbar, U.; Markoli, B.; Poberaj, I.; Zalar, A.; Kosec, L.; Spaić, S. Formation of functional groups on graphite during oxygen plasma treatment. Appl. Surf. Sci. 2006, 253, 1861-1865. [CrossRef]

29. Cvelbar, U. Interaction of non-equilibrium oxygen plasma with sintered graphite. Appl. Surf. Sci. 2013, 269, 33-36. [CrossRef]

30. Moučka, R.; Goňa, S.; Sedlačík, M. Accurate Measurement of the True Plane-Wave Shielding Effectiveness of Thick Polymer Composite Materials via Rectangular Waveguides. Polymers 2019, 11, 1603. [CrossRef] [PubMed]

31. Panda, J.R.; Kshetrimayum, R.S. An F-shaped printed monopole antenna for dual-band RFID and WLAN applications. Microw. Opt. Technol. Lett. 2011, 53, 1478-1481. [CrossRef]

32. Chung, K.T.; Sabo, A.; Pica, A.P. Electrical permittivity and conductivity of carbon black-polyvinyl chloride composites. J. Appl. Phys. 1982, 53, 6867-6879. [CrossRef]

33. Jou, W.-S.; Cheng, H.-Z.; Hsu, C.-F. The electromagnetic shielding effectiveness of carbon nanotubes polymer composites. J. Alloy. Compd. 2007, 434, 641-645. [CrossRef]

Publisher's Note: MDPI stays neutral with regard to jurisdictional claims in published maps and institutional affiliations.

(C) 2020 by the authors. Licensee MDPI, Basel, Switzerland. This article is an open access article distributed under the terms and conditions of the Creative Commons Attribution (CC BY) license (http://creativecommons.org/licenses/by/4.0/). 